\title{
Rationale for and approach to preoperative opioid weaning: a preoperative optimization protocol
}

\author{
Heath McAnally ${ }^{1,2}$
}

\begin{abstract}
The practice of chronic opioid prescription for chronic non-cancer pain has come under considerable scrutiny within the past several years as mounting evidence reveals a generally unfavorable risk to benefit ratio and the nation reels from the grim mortality statistics associated with the opioid epidemic. Patients struggling with chronic pain tend to use opioids and also seek out operative intervention for their complaints, which combination may be leading to increased postoperative "acute-on-chronic" pain and fueling worsened chronic pain and opioid dependence.

Besides worsened postoperative pain, a growing body of literature, reviewed herein, indicates that preoperative opioid use is associated with significantly worsened surgical outcomes, and severely increased financial drain on an already severely overburdened healthcare budget. Conversely, there is evidence that preoperative opioid reduction may result in substantial improvements in outcome. In the era of accountable care, efforts such as the Enhanced Recovery After Surgery (ERAS) protocol have been introduced in an attempt to standardize and facilitate evidencebased perioperative interventions to optimize surgical outcomes. We propose that addressing preoperative opioid reduction as part of a targeted optimization approach for chronic pain patients seeking surgery is not only logical but mandatory given the stakes involved. Simple opioid reduction/abstinence however is not likely to occur in the absence of provision of viable and palatable alternatives to managing pain, which will require a strong focus upon reducing pain catastrophization and bolstering self-efficacy and resilience.

In response to a call from our surgical community toward that end, we have developed a simple and easy-to-implement outpatient preoperative optimization program focusing on gentle opioid weaning/elimination as well as a few other high-yield areas of intervention, requiring a minimum of resources.
\end{abstract}

Keywords: Preoperative, Chronic pain, Opioid, Weaning, Optimization, Outcomes, Length of stay, Prehabilitation, Opioidinduced hyperalgesia, Biopsychosocial

\section{Background}

America's opioid problem remains unrelenting, insidious, and without a clear solution in sight. One particular arena where aggressive intervention may have significant impact is the perioperative period. Within the surgical population, a large proportion of patients (as many as 33-70\% (Tye et al. 2017)) seeking elective operations are already using chronic prescription opioids. These patients have been shown to demand greater doses and duration of opioid therapy postoperatively (VanDenKerkhof et al. 2012;

\footnotetext{
Correspondence: hmcan@uw.edu

${ }^{1}$ Northern Anesthesia \& Pain Medicine, LLC, 10928 Eagle River Rd \#240, Eagle River, AK 99577, USA

${ }^{2}$ Department of Anesthesiology and Pain Medicine, University of

Washington, Box 356540, Seattle, WA 98195-6540, USA
}

Carroll et al. 2012; Hah et al. 2015; Rozet et al. 2014; Lawrence et al. 2008b; Armaghani et al. 2014). This may simply represent the presence of more serious "pain generators" leading to greater opioid consumption both pre- and postoperatively, or may represent a more complex scenario with compromised resilience and self-efficacy, increased underlying emotional and psychological distress, and frank opioid dependence driving the process. Chronic opioid use also reliably confers tolerance to the agent's analgesic properties (Collett 1998; Adriaensen et al. 2003; Chang et al. 2007; Williams et al. 2013) leading to less effective perioperative pain management and often disproportionate pain. Furthermore, there is growing evidence that chronic opioid use increases pain sensitivity-currently labeled opioid-induced hyperalgesia $(\mathrm{OIH})$-thus leading to a 
pernicious cycle of increased demand for mu-receptor agonism/narcotization which in turn increases pain which increases demand (Angst and Clark 2006; Lee et al. 2011).

Seasoned surgeons of all disciplines have learned that the risk to benefit ratio of surgery may lie toward the harmful for elective procedures in patients who are morbidly obese, nutritionally deficient, deconditioned/"sarcopenic", tobacco users, etc. A growing body of evidence (reviewed below) indicates that even after adjusting for many of these obvious confounders, chronic opioid use also predisposes to poor surgical outcomes including immediate postoperative complications such as infection and other physiologic perturbation (e.g., ileus and respiratory suppression with atelectasis and pneumonia) but also long-term issues such as compromised wound healing and reduced arthroplasty or intervertebral fusion success.

We propose that bringing opioid-dependent patients to the operating room for elective surgery carries an unacceptably high risk of conferring "acute-on-chronic pain" much like unaddressed hypovolemia in the chronic renalinsufficient patient invites acute-on-chronic renal failure. We also propose that among numerous high-yield targets for optimizing surgical outcome (e.g., tobacco cessation and nutritional prehabilitation), opioid reduction or elimination deserves particular consideration in the context of the growing public health problem of misuse, abuse, and dependence. Finally, we propose that deferring elective surgery until adequate preoperative optimization (i.e., reduction or elimination if possible) of opioid use, just like delaying for body mass index (BMI) improvements or tobacco cessation, comprises wise stewardship of private and public monies funding healthcare.

\section{Survey}

We surveyed 62 local surgeons (with 48 respondents) from the disciplines of general surgery, gynecology, neurosurgery, ophthalmology, orthopedics, otolaryngology, plastic surgery, and urology to see how long they would be willing to defer elective operations in unprepared patients, and also what the top three to five issues (modifiable risk factors) were they would like to see optimized prior to elective surgery. The results are shown in Figs. 1 and 2. The range of perceived acceptable preoperative delay for non-urgent problems ranged from 4 weeks to indefinite, with the majority of surgeons favoring waiting longer than 23 months if necessary to optimize their patients. Among the common modifiable risk factors that our surgeons prioritized for preoperative optimization, the most frequently identified issues were tobacco use, opioid use, obesity, unrealistic expectations and other psychological factors, deconditioning, and diabetes or other systemic diseases.

A weighted value ("optimization importance factor") was created for each variable reported by our surgeon population by multiplying the number of surgeons reporting it by

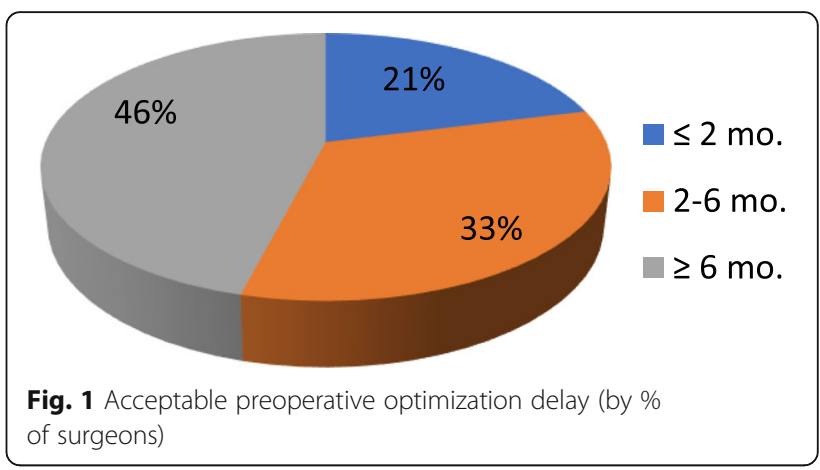

a numeric scale ranking (in descending order from 5 to 1 ) of prioritization.

\section{Literature review}

Over the past 10 years, multiple reports (Armaghani et al. 2014; Lawrence et al. 2008a; Anderson et al. 2009; Roullet et al. 2009; Zywiel et al. 2011; Raebel et al. 2013; Pivec et al. 2014; Menendez et al. 2015; Morris et al. 2015; Hina et al. 2015; Aasvang et al. 2016; Morris et al. 2016; Sing et al. 2016; Zarling et al. 2016; Nguyen et al. 2016; Faour et al. 2017; Ben-Ari et al. 2017; Villavicencio et al. 2017; Waljee et al. 2017; Smith et al. 2017; Rozell et al. 2017; Chan et al. 2017; Cheah et al. 2017) have noted a generally consistent association between preoperative chronic opioid use and worsened postoperative outcomes. These studies are summarized in Table 1, and individual studies of interest are briefly presented below. A negative study is discussed first, however, along with criticism.

Kelly et al.'s (2015) retrospective cohort study indicated no evident difference in pain or disability 2 years out from cervical disc replacement or interbody fusion patients stratified into those using "weak" $(n=762)$ vs. "strong" ( $n=226)$ opioids. A third control arm comprised only 16 individuals who were opioid-naïve going into surgery. The opioid categorization however was arbitrary and did not accurately reflect potency (e.g., meperidine which is considerably less potent than hydromorphone was placed in the "strong opioid" group whereas hydrocodone, essentially equipotent to morphine, was placed in the "weak opioid" group). Furthermore, there was undoubtedly considerable overlap between the two groups in terms of actual equivalent opioid dosage. This study must then be interpreted with considerable skepticism.

Menendez et al. (2015) performed a tremendously powered retrospective analysis of 15,901 opioid-dependent individuals undergoing various arthroplasties or spinal fusion operations, compared to over 9 million controls. After adjusting for demographic, comorbidity, hospital, and operative variables, they noted that opioid dependence was statistically significantly associated with increased morbidity and mortality. Increased hospital length of stay (LOS) and 
- Optimization Importance Factor

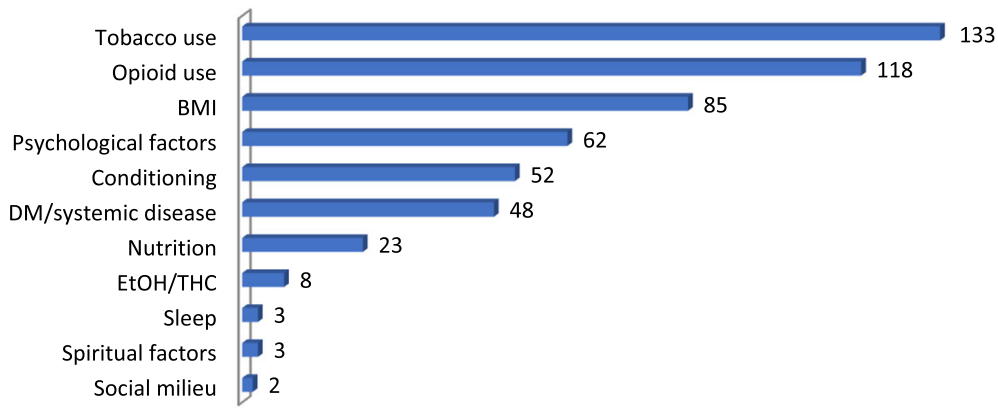

Fig. 2 Preoperative variables of concern to surgeons

discharge to rehabilitation facilities also correlated with opioid dependence.

A small but interesting study by Hina et al. (2015) adds to the literature on opioid-induced hyperalgesia and demonstrated that preoperative opioid use is associated with demonstrable $\mathrm{OIH}$ prior to operation, and despite a more aggressive intraoperative anesthetic approach (e.g., inclusion of ketamine into the anesthetic), patients using chronic preoperative opioids displayed greater postoperative pain and increased opioid demand, consistent with the experience of most clinicians and the literature.

Sing et al. (2016) in a subgroup analysis examined the negative consequences of preoperative extended-release/ long-term opioid use in relation to postoperative outcomes. They reported that of 116 total knee and hip arthroplasty patients using preoperative opioids, there was a trend noted for more severe outcomes (increased postoperative pain and opioid consumption, increased hospital LOS, increased admission to rehabilitation facilities, worsened surgical outcomes including arthrofibrosis and periprosthetic fractures) in the extended-release/long-acting opioid-using subgroup compared to the immediate-release opioid-using group.

Ben-Ari et al. (2017) in another highly powered study demonstrated that 12,772 patients undergoing total knee arthroplasty who had been using chronic preoperative opioids were significantly more likely to undergo revision arthroplasty compared to 19,864 controls, results echoed by other studies as listed in Table 1 .

A few studies have examined the associated between preoperative opioid use and economic outcomes. Waljee et al. (2017) performed a retrospective analysis of nearly 200,000 patients undergoing various general surgical operations and hysterectomies. The patients using chronic preoperative opioids $(n=17,577)$ had significantly longer hospital LOS, increased incidence of discharge to rehabilitation facilities and hospital readmission, and generated greater than double the financial costs than 182,428 controls, after adjusting for numerous psychosocial variables. Faour et al.
(2017) and Tye et al. (2017) have demonstrated that cervical and lumbar spine surgical patients, respectively, who used chronic preoperative opioids had significantly lower incidence of return to work than matched cohorts who did not use chronic preoperative opioids.

Finally, a very interesting study by Nguyen et al. (2016) suggests that preoperative opioid reduction may prove protective against these negative outcomes. Forty-one patients who successfully weaned their opioid burden prior to surgery by at least $50 \%$ were compared to 41 opioiddependent patients who did not, and 41 opioid-naïve controls. The intervention group had outcomes comparable to the opioid-naive group, with both of those two groups demonstrating significantly improved pain and functional outcomes compared to the patient group that did not reduce their opioid use preoperatively. This is the first study to demonstrate efficacy of preoperative opioid reduction.

\section{Discussion}

The International Association for the Study of Pain has labeled 2017 the Global Year Against Pain After Surgery (International Association for the Study of Pain 2017). This laudable, ambitious approach highlights well-accepted and traditional objectives such as aggressive perioperative multimodal analgesia, and its goals are echoed in the philosophy of constructs such as Toronto's Transitional Pain Service and the American Society of Anesthesiologists' Perioperative Surgical Home (Katz et al. 2015; Desebbe et al. 2016). As important as such diversification of response is, it still comprises response and is thus at least theoretically inferior to an approach of proactive "pain prehabilitation," certainly within the chronic pain patient population.

\section{The biologic complexity of chronic pain, and opioid-induced hyperalgesia}

Pain is a complex and subjective experience now wellknown to occur outside of the context of nociception, and with considerable potential for both amplification and suppression from the central nervous system (Latremoliere 
Table 1 Studies reporting outcomes following preoperative opioid use

\begin{tabular}{|c|c|c|c|}
\hline Authors & Year & Discipline & Findings \\
\hline $\begin{array}{l}\text { Lawrence } \\
\text { et al. }\end{array}$ & 2008 & Spine & $\begin{array}{l}47 \text { chronic opioid-using patients experienced significantly } \\
\text { worsened outcomes of pain and disability postoperatively } \\
\text { compared to } 44 \text { non-opioid-using patients }\end{array}$ \\
\hline $\begin{array}{l}\text { Anderson } \\
\text { et al. }\end{array}$ & 2009 & Spine & $\begin{array}{l}\text { Logistical regression model of } 488 \text { ACDF patients revealed } \\
\text { "weak" preoperative opioid use as an independently significant } \\
\text { negative predictive variable for postoperative neck disability }\end{array}$ \\
\hline $\begin{array}{l}\text { Roullet } \\
\text { et al. }\end{array}$ & 2009 & Orthopedics & $\begin{array}{l}12 \text { chronic preoperative opioid-using patients had greater } \\
\text { postoperative opioid consumption and phantom limb pain } \\
\text { than } 10 \text { non-opioid-using controls }\end{array}$ \\
\hline $\begin{array}{l}\text { Zywiel } \\
\text { et al. }\end{array}$ & 2011 & Orthopedics & $\begin{array}{l}45 \text { TKA patients using opioids preoperatively had significantly } \\
\text { greater postoperative dysfunction and complications including } \\
\text { need for revision compared to non-opioid-using controls }\end{array}$ \\
\hline $\begin{array}{l}\text { Raebel } \\
\text { et al. }\end{array}$ & 2013 & Bariatric surgery & $\begin{array}{l}77 \% \text { of } 933 \text { chronic opioid-using bariatric surgery patients } \\
\text { continued to use opioids at } 12 \text {-month postoperative follow-up } \\
\text { and generally at higher doses }\end{array}$ \\
\hline $\begin{array}{l}\text { Pivec } \\
\text { et al. }\end{array}$ & 2014 & Orthopedics & $\begin{array}{l}54 \text { THA patients using opioids preoperatively had significantly } \\
\text { greater postoperative pain and opioid consumption, increased } \\
\text { hospital LOS, worsened postoperative function and increased } \\
\text { arthroplasty failure compared to non-opioid-using controls }\end{array}$ \\
\hline $\begin{array}{l}\text { Armaghani } \\
\text { et al. }\end{array}$ & 2014 & Spine & $\begin{array}{l}\text { Logistic regression model of } 583 \text { patients demonstrated that of } \\
321 \text { patients using chronic preoperative opioids, "increasing } \\
\text { preoperative use" correlated with ongoing opioid dependence } \\
12 \text { months postoperatively }\end{array}$ \\
\hline $\begin{array}{l}\text { Kelly } \\
\text { et al. }\end{array}$ & 2015 & & $\begin{array}{l}762 \text { "weak opioid" (codeine, propoxyphene, hydrocodone), } 226 \\
\text { "strong opioid" (meperidine, morphine, oxycodone) and } 16 \text { non-opioid-using } \\
\text { patients showed no significant differences in pain and disability at 2-year follow-up }\end{array}$ \\
\hline $\begin{array}{l}\text { Menendez } \\
\text { et al. }\end{array}$ & 2015 & Orthopedics & $\begin{array}{l}\text { 15,901 THA, TKA, TSA, and spine fusion patients with a diagnosis of } \\
\text { opioid dependence or abuse had statistically significantly worsened } \\
\text { morbidity and mortality outcomes than over } 9 \text { million controls }\end{array}$ \\
\hline $\begin{array}{l}\text { Hina } \\
\text { et al. }\end{array}$ & 2015 & Orthopedics & $\begin{array}{l}28 \text { opioid-using orthopedic patients displayed significantly greater } \\
\text { hyperalgesia preoperatively, reported greater pain and consumed } \\
\text { significantly more opioids postoperatively than } 40 \text { non-opioid-using controls }\end{array}$ \\
\hline Morris et al. & 2015 & Orthopedics & $\begin{array}{l}32 \text { Reverse TSA patients using chronic preoperative opioids had } \\
\text { significantly worse outcomes of postoperative shoulder function } \\
\text { including ROM compared to } 36 \text { controls }\end{array}$ \\
\hline Morris et al. & 2016 & Orthopedics & $\begin{array}{l}60 \text { TSA patients using chronic preoperative opioids had significantly } \\
\text { worse outcomes of postoperative shoulder function including ROM } \\
\text { and decreased satisfaction compared to } 164 \text { controls }\end{array}$ \\
\hline Sing et al. & 2016 & Orthopedics & $\begin{array}{l}116 \text { TKA and THA patients using preoperative opioids had significantly } \\
\text { worse postoperative pain and increased opioid consumption, increased } \\
\text { hospital LOS, admission to rehabilitation facilities, worsened surgical } \\
\text { outcomes (including arthrofibrosis and periprosthetic fractures) compared } \\
\text { to } 58 \text { non-opioid-using controls }\end{array}$ \\
\hline $\begin{array}{l}\text { Aasvang } \\
\text { et al. }\end{array}$ & 2016 & Orthopedics & $\begin{array}{l}58 \text { TKA patients using chronic preoperative opioids had significantly } \\
\text { increased pain and opioid requirements within the first week of surgery } \\
\text { compared to } 57 \text { non-opioid-using controls }\end{array}$ \\
\hline $\begin{array}{l}\text { Zarling } \\
\text { et al. }\end{array}$ & 2016 & Orthopedics & $\begin{array}{l}106 \text { TKA and THA using chronic preoperative opioids had greater likelihood } \\
\text { of postoperative rehabilitation facility admission and significantly increased } \\
\text { continued use of opioids } 12 \text { months postoperatively than } 209 \text { non-opioid-using controls }\end{array}$ \\
\hline
\end{tabular}

$\begin{array}{lcl}\begin{array}{l}\text { Nguyen } \\ \text { et al. }\end{array} & 2016 & \text { Orthopedics } \\ \begin{array}{l}\text { Faour } \\ \text { et al. }\end{array} & 2017 & \text { Spine } \\ \begin{array}{l}\text { Tye } \\ \text { et al. }\end{array} & 2017 & \text { Spine } \\ \begin{array}{l}\text { Ben-Ari } \\ \text { et al. }\end{array} & 2017 & \text { Orthopedics } \\ & & \end{array}$

77 ACDF patients using chronic preoperative opioids had significantly lower incidence of return to work than 204 non-opioid-using controls

80 lumbar decompression patients from the worker's compensation population using chronic preoperative opioids greater than 3 months were significantly less likely to return to work than those $(n=60)$ using opioids less than 3 months preoperatively 12,772 TKA patients using chronic preoperative opioids had significantly higher incidence of revision than 19,864 non-opioid-using controls 
Table 1 Studies reporting outcomes following preoperative opioid use (Continued)

\begin{tabular}{|c|c|c|c|}
\hline Authors & Year & Discipline & Findings \\
\hline $\begin{array}{l}\text { Smith } \\
\text { et al. }\end{array}$ & 2017 & Orthopedics & $\begin{array}{l}36 \text { TKA patients using chronic preoperative opioids had significantly } \\
\text { worse pain } 6 \text { months postoperatively compared to } 120 \text { non-opioid-using controls }\end{array}$ \\
\hline Waljee et al. & 2017 & General surgery & $\begin{array}{l}17,577 \text { patients using chronic preoperative opioids had significantly } \\
\text { longer hospital LOS, increased incidence of discharge to rehabilitation } \\
\text { facilities and hospital readmission, and generated significantly higher } \\
\text { financial expenditures than } 182,428 \text { controls }\end{array}$ \\
\hline Villavicencio et al. & 2017 & Spine & $\begin{array}{l}60 \text { TLIF patients using chronic preoperative opioids had significantly } \\
\text { greater } 12 \text {-month postoperative pain and disability compared to } 33 \\
\text { non-opioid-using controls }\end{array}$ \\
\hline Rozell et al. & 2017 & Orthopedics & $\begin{array}{l}275 \text { TKA and THA patients using chronic preoperative opioids } \\
\text { (compared to } 527 \text { controls) were shown in a regression model } \\
\text { to be more likely to require increase perioperative opioids and } \\
\text { increased hospital LOS as well as suffer higher incidence of complications }\end{array}$ \\
\hline Chan et al. & 2017 & Orthopedics & $\begin{array}{l}36 \text { TKA patients maintained on methadone preoperatively required } \\
\text { greater postoperative opioids and inpatient pain management consultation, } \\
\text { and had increased hospital LOS compared to } 36 \text { matched controls }\end{array}$ \\
\hline Cheah et al. & 2017 & Orthopedics & $\begin{array}{l}138 \text { TSA patients using chronic preoperative opioids had significantly } \\
\text { greater postoperative pain and opioid use compared to } 124 \text { non-opioid-using controls }\end{array}$ \\
\hline
\end{tabular}

and Woolf 2009; Tracey and Mantyh 2007; Heinricher et al. 2009). While acute/nociceptive pain comprises a warning system alerting the organism to adopt avoidant behavior, it is now widely accepted (and supported by functional imaging evidence) that chronic pain for the most part represents maladaptive neuroplastic changes at the dorsal horn, and multiple higher (brain) centers including amygdala, hippocampus, insula, cingulate, and other parietal cortex areas and the prefrontal cortex (Flor et al. 1997; Tinazzi et al. 1998; Apkarian et al. 2004; Apkarian et al. 2005; Schmidt-Wilcke 2008; Rodriguez-Raecke et al. 2009; Baliki et al. 2010; Malinen et al. 2010; Apkarian et al. 2011; Farmer et al. 2012; Baliki et al. 2012).

Chronic opioid use is believed to reinforce this pathology, and again, functional neuroimaging studies seem to support shared neuroanatomic pathways and perturbances (Wanigasekera et al. 2011; Younger et al. 2011).

Chronic opioid use has also been shown to increase pain sensitivity via a process known as opioid-induced hyperalgesia $(\mathrm{OIH})$. Distinct from tolerance, which represents an increasing threshold for analgesic responsiveness, OIH represents a reduced threshold for pain perception. Teleologically, the prolonged and imbalanced exogenous suppression of pain impulses to the brain should result in a reactionary increase in sensitivity to maintain homeostasis of this most critical protective sense. OIH is likely multifactorial with a host of postulated mechanisms including structural and functional alterations in opioid receptors, long-term potentiation at the dorsal horn, glial-mediated neuroinflammation, enhanced descending pain facilitation, and epigenetic factors (Lee et al. 2011; Roeckel et al. 2016; Weber et al. 2017). Once thought to require months of exposure to opioids, it is now recognized from animal and human investigations that $\mathrm{OIH}$ may occur with exposure as brief as days (Angst and Clark 2006; Compton et al. 2003;
Cooper et al. 2012) and the recent widespread use of intraoperative remifentanil infusions has demonstrated that exposure on the order of hours is sufficient (Guignard et al. 2000; Angst et al. 2003). There may be a dose-response effect (Salengros et al. 2010; Fechner et al. 2013; Fletcher and Martinez 2014; Mauermann et al. 2016).

A specific association between chronic preoperative opioid use and postoperative hyperalgesia has been demonstrated recently (Hina et al. 2015; Chapman et al. 2011). This may result from preoperative OIH persisting into the postoperative period or may be mediated more acutely by requisite increased intra- and postoperative opioid doses. The association may also be confounded in the perioperative setting by inadequate analgesia resulting from tolerance; increased immediate postoperative pain intensity has been shown to correlate with increased incidence of persistent postoperative hyperalgesia (Malik et al. 2017; Weinbroum 2017).

Regardless of the mechanisms involved, the study by Nguyen et al. (2016) showing improved pain and functional outcomes after even a $50 \%$ reduction in preoperative opioid burden argues convincingly in the context of the other literature reviewed herein for a concerted effort toward preoperative opioid reduction if not elimination. Additional supporting evidence for this tactic comes from the recent demonstration that downtitration of remifentanil infusion rates is associated with a lower incidence of OIH (Comelon et al. 2016).

\section{The psychosocial complexity of chronic pain and opioid misuse}

Chronic pain is also associated with psychological distress such as anxiety, post-traumatic stress disorder, borderline personality disorders, and to a lesser degree depression (Fishbain et al. 1998; Von Korff et al. 2005; 
Gureje et al. 2008; Bushnell et al. 2013; Simons et al. 2014). The reported severity of such chronic pain has been shown to correlate much more closely with these psychosocial variables than with somatic contributors including injury severity, which has in fact been shown in several studies to be non-predictive (Harris et al. 2007; Jenewein et al. 2009; Trevino et al. 2013). These psychological/behavioral comorbidities have also been shown to predict chronic postoperative pain specifically (Kleiman et al. 2011; Theunissen et al. 2012; Attal et al. 2014; Hoofwijk et al. 2015).

The distinct construct of pain catastrophizing has received significant attention recently in the arenas of pain management and perioperative medicine. Pain catastrophizing is defined as persistent negative cognitive and affective responses to actual or anticipated pain (Quartana et al. 2009) and incorporates various degrees of magnification, rumination, and perception of helplessness (Sullivan et al. 1995). Pain catastrophizing and learned helplessness correlate with many of the underlying psychiatric comorbidities mentioned above and also independently confer worsened postoperative pain (Theunissen et al. 2012; Ip et al. 2009; Khan et al. 2011; Vissers et al. 2012; Denison et al. 2004) and surgical outcomes (Abbot et al. 2011, Coronado et al. 2015, Teunis et al. 2015)

All of these behavioral comorbidities are strongly associated with chronic opioid use, misuse, and dependence (Turk et al. 2008; Becker et al. 2008; Goldner et al. 2014; Gross et al. 2016; Arteta et al. 2016; McAnally 2017) and in fact have been shown repeatedly to be the most robust predictors (Martins et al. 2012; Katz et al. 2013; Blanco et al. 2013).

A final consideration related to the complex association of psychopathology, chronic pain, opioid use, and the perioperative arena is that patients suffering with chronic pain are more likely to seek not only opioid prescriptions, but also operative intervention. Among those patients struggling with chronic pain is a disproportionate number of individuals plagued with catastrophic thinking regarding pain, as well as poor self-efficacy. To quote Beth Darnall, a leading contemporary researcher in the field, "pain catastrophizing may speed the path to surgery while simultaneously undermining surgical response" (Darnall 2016). In other words, the path to the operating room may be disproportionately self-selected by the very people who are least likely to benefit from it, or who are the least prepared at any rate.

Over-eager desire for surgical intervention and persistent seeking of opioid prescriptions are both more likely to be associated with an external locus of control. While impossible to measure objectively, this lack of self-efficacy may in fact be the most important independent variable.

\section{The rationale for preoperative opioid cessation and an effective biopsychosocial substitute}

An increasing number of publications as well as our local survey of surgeons indicate the importance of preoperative opioid reduction. The survey results may be biased somewhat in terms of the importance associated to preoperative opioid reduction or elimination given our reputation and that of our preoperative optimization program within the community. Nonetheless, the literature does support both plausibility and rationality of this objective, and at an anecdotal level, anyone involved in perioperative care for more than a handful of years has learned the challenges involved in rendering opioidtolerant patients comfortable in the post-anesthesia care unit and the ward, and surgeons and pain physicians are well aware of the difficulties they face afterward. As discussed above, there is growing recognition also that chronic preoperative opioid use confers postoperative problems beyond simple analgesic compromise. However, answering the question at hand, whether preoperative opioid reduction/elimination is beneficial in terms of outcome may be more difficult than appears on the surface. First of all, randomization is almost certainly not going to occur-patients either are or are not willing to reduce or eliminate their opioids preoperatively. Second, blinding would be nearly impossible in that the high probability of withdrawal symptoms would likely unmask treatment arms. Whether or not preoperative opioid reduction is beneficial must then most likely be judged from non-randomized prospective or retrospective studies, the plausibility of compelling "reverse" evidence such as the studies discussed herein, and common sense given the known associations between chronic opioid use and its harms.

Beyond mere opioid reduction/cessation, in view of the complex risk factors for chronic pain discussed briefly above, it stands to reason (and has been advocated by numerous experts, consensus groups, and clinical practice guidelines) (Veterans Health Administration and Department of Defense 2002; Chou et al. 2007; Federation of State Medical Boards 2013; United States Department of Health and Human Services 2016; Manchikanti et al. 2017) that a biopsychosocial-spiritual paradigm with particular focus upon enhancing resilience and diversify coping skills is required. Simply removing opioids without providing effective substitute coping mechanisms will invariably lead to noncompliance and dropout. A systematic, rigorous (e.g., weekly visit) program of opioid reduction/withdrawal palliation needs to be coupled with basic preoperative counseling addressing the replacement of multifactorial "wellness-killers" (e.g., poor self-valuation and esteem, unaddressed psychopathology, poor sleep, poor nutrition, sedentary lifestyle, tobacco use) with proactive 
steps supporting personal responsibility for health and wellness.

Growing recognition of the disproportionate impact of chronic pain syndromes upon operative outcomes in Canada has led to the establishment of what appears to be a promising, comprehensive approach to perioperative pain management for chronic pain patients with the Toronto General Transitional Pain Service (TPS) (Katz et al. 2015). The current iteration of the TPS involves five anesthesiology-based pain physicians, a palliative care specialist/family physician, two clinical psychologists and trainees, three acute pain nurse practitioners, two physical therapists with expertise in acupuncture, an exercise physiologist, and administrative staff (Katz et al. 2015).

The American Society of Anesthesiologists, among other organizations, has championed the concept of a Perioperative Surgical Home (PSH) (Desebbe et al. 2016) which is intended to address multiple perioperative health deficits at an institutional level. One of the theoretical functions of a PSH would be to address perioperative chronic pain management optimization including opioid reduction (Vetter and Kain 2017). A significant practical barrier however in the USA (with payer source fragmentation and limitations of reimbursement allocation) is actually coming up with the resources for such an effort. As noted by Vetter and Kain,

How will an organization finance these additional resources necessary for a Transitional Pain Service? ... A small community hospital may be hard-pressed to mobilize the comprehensive services and personnel required to successfully implement a full-scale perioperative Transitional Pain Service.

We propose that moving such perioperative chronic pain optimization functions outside of the institution to a smaller, leaner paradigm shaped by market pressures including outcomes-driven referral patterns will result in more efficient use of resources and improved care. Toward that end, we have created and begun implementation of a multidisciplinary preoperative optimization program for chronic pain patients focusing on a few highyield areas of intervention, with opioid reduction and pain catastrophizing as two of the top priorities (as well as tobacco cessation and diet and activity improvements). The current iteration of the program comprises a 10-12-week course and incorporates traditional preoperative assessment and consultation issues (e.g., cardiac clearance and endocrinologic optimization) into a basic "wellness program" with simple, graded, measurable objectives including gentle opioid weaning along the lines of the fairly standard $10 \%$ per week paradigm (Manchikanti et al. 2017). Evidence from the behavioral world indicates that it takes at least 12 weeks to change habits (Lally et al. 2010); moving such "pain prehabilitation" into the outpatient realm and allowing for adequate optimization time beforehand allows for such and furthermore overcomes the institutional-level problem of lack of resources by placing this critical component of healthcare into the hands of invested providers. While the cost of a dozen or so outpatient follow-up visits may seem formidable up front, it is exceeded by the cost of a single extra day in the hospital and pales in comparison to a canceled operation, or worst of all an adverse outcome.

\section{Conclusions}

The literature increasingly supports an association between preoperative opioid use and worsened postoperative pain, surgical outcomes, length of stay, and financial costs. Conversely, there is evidence that preoperative opioid reduction may result in substantial improvements in outcomes. In order to optimize chronic pain patients seeking surgery, we propose that addressing preoperative opioid reduction (among a handful of high-yield risk factors) is not only logical but also imperative. Simple opioid reduction/abstinence however is not likely to occur in the absence of provision of viable and palatable alternatives to managing pain, which will require a strong focus upon reducing pain catastrophization and bolstering self-efficacy and resilience, and nurturing a commitment to overall biopsychosocialspiritual health. We have developed a simple and easy-toimplement outpatient preoperative optimization program focusing on gentle opioid weaning/elimination along with tobacco cessation, "de-catastrophization" and expectation management, and nutritional, sleep, and conditioning "prehabilitation." This 3-month program requires a minimum of resources and promises a good return on investment for chronic pain patients willing to exert a nominal degree of effort toward improving their surgical experience and outcome.

\section{Abbreviations}

BMI: Body mass index; ERAS: Enhanced Recovery After Surgery; LOS: Length of stay; OIH: Opioid-induced hyperalgesia; PSH: Perioperative Surgical Home; TPS: Transitional Pain Service

\section{Acknowledgements \\ Jeanne Chapman, RN assisted in gathering of local surgeon data.}

Availability of data and material

The datasets used and/or analyzed during the current study are available from the corresponding author on reasonable request.

\section{Funding}

Not applicable.

\section{Authors' contributions}

The entire article was conceived and written by Dr. McAnally along with gathering of local surgeon data.

Ethics approval and consent to participate Not applicable. 


\section{Consent for publication}

Not applicable.

\section{Competing interests}

Dr. McAnally is the Medical Director of Northern Anesthesia \& Pain Medicine, LLC, which is one of the two organizations that have created, copyrighted, and implemented the Valeras@ Preoperative Optimization Program described herein.

\section{Publisher's Note}

Springer Nature remains neutral with regard to jurisdictional claims in published maps and institutional affiliations.

Received: 11 September 2017 Accepted: 31 October 2017

Published online: 22 November 2017

\section{References}

Aasvang EK, Lunn TH, Hansen TB, Kristensen PW, Solgaard S, Kehlet H. Chronic pre-operative opioid use and acute pain after fast-track total knee arthroplasty. Acta Anaesthesiol Scand. 2016;60:529-36.

Abbott AD, Tyni-Lenne R, Hedlund R. Leg pain and psychological variables predict outcome 2-3 years after lumbar fusion surgery. Eur Spine J. 2011;20:1626-34.

Adriaensen $\mathrm{H}$, Vissers K, Noorduin H, Meert T. Opioid tolerance and dependence: an inevitable consequence of chronic treatment? Acta Anaesthesiol Belg. 2003;54:37-47.

Anderson PA, Subach BR, Riew KD. Predictors of outcome after anterior cervical discectomy and fusion: a multivariate analysis. Spine (Phila Pa 1976). 2009;34:161-6.

Angst MS, Clark JD. Opioid-induced hyperalgesia: a qualitative systematic review. Anesthesiology. 2006;104:570-87.

Angst MS, Koppert W, Pahl I, Clark DJ, Schmelz M. Short-term infusion of the muopioid agonist remifentanil in humans causes hyperalgesia during withdrawal. Pain. 2003; 106:49-57.

Apkarian AV, Bushnell MC, Treede RD, Zubieta JK. Human brain mechanisms of pain perception and regulation in health and disease. Eur J Pain. 2005;9:463-84.

Apkarian AV, Hashmi JA, Baliki MN. Pain and the brain: specificity and plasticity of the brain in clinical chronic pain. Pain. 2011;152(3 Suppl):S49-64.

Apkarian AV, Sosa Y, Sonty S, Levy RE, Harden RN, Parrish TB, et al. Chronic back pain is associated with decreased prefrontal and thalamic gray matter density. J Neurosci. 2004:24:10410-5.

Armaghani SJ, Lee DS, Bible JE, Archer KR, Shau DN, Kay H, et al. Preoperative opioid use and its association with perioperative opioid demand and postoperative opioid independence in patients undergoing spine surgery. Spine (Phila Pa 1976). 2014;39(25):E1524-30. https://doi.org/10.1097/BRS. 0000000000000622

Arteta J, Cobos B, Hu Y, Jordan K, Howard K. Evaluation of how depression and anxiety mediate the relationship between pain catastrophizing and prescription opioid misuse in a chronic pain population. Pain Med. 2016;17:295-303.

Attal N, Masselin-Dubois A, Martinez V, Jayr C, Albi A, Fermanian J, et al. Does cognitive functioning predict chronic pain? Results from a prospective surgical cohort. Brain. 2014;137:904-17.

Baliki MN, Geha PY, Fields HL, Apkarian AV. Predicting value of pain and analgesia: nucleus accumbens response to noxious stimuli changes in the presence of chronic pain. Neuron. 2010;66(1):149-60. https://doi.org/10.1016/ j.neuron.2010.03.002.

Baliki MN, Petre B, Torbey S, Herrmann KM, Huang L, Schnitzer TJ, et al. Corticostriatal functional connectivity predicts transition to chronic back pain Nat Neurosci. 2012;15:1117-9.

Becker WC, Sullivan LE, Tetrault JM, Desai RA, Fiellin DA. Non-medical use, abuse and dependence on prescription opioids among U.S. adults: psychiatric, medical and substance use correlates. Drug Alcohol Depend. 2008;94:38-47.

Ben-Ari A, Chansky H, Rozet I. Preoperative opioid use is associated with early revision after total knee arthroplasty: a study of male patients treated in the veterans affairs system. J Bone Joint Surg Am. 2017;99:1-9.

Blanco C, Rafful C, Wall MM, Jin CJ, Kerridge B, Schwartz RP. The latent structure and predictors of non-medical prescription drug use and prescription drug use disorders: a national study. Drug Alcohol Depend. 2013;133:473-9.

Bushnell MC, Ceko M, Low LA. Cognitive and emotional control of pain and its disruption in chronic pain. Nat Rev Neurosci. 2013;14:502-11.

Carroll I, Barelka P, Wang CK, Wang BM, Gillespie MJ, McCue R. A pilot cohort study of the determinants of longitudinal opioid use after surgery. Anesth Analg. 2012;115:694-702.
Chan FJ, Schwartz AM, Wong J, Chen C, Tiwari B, Kim SJ. Use of chronic methadone before total knee arthroplasty. J Arthroplast. 2017;32:2105-7.

Chang G, Chen L, Mao J. Opioid tolerance and hyperalgesia. Med Clin North Am. 2007:91:199-211.

Chapman CR, Davis J, Donaldson GW, Naylor J, Winchester D. Postoperative pain trajectories in chronic pain patients undergoing surgery: the effects of chronic opioid pharmacotherapy on acute pain. J Pain. 2011;12:1240-6.

Cheah JW, Sing DC, McLaughlin D, Feeley BT, Ma CB, Zhang AL. The perioperative effects of chronic preoperative opioid use on shoulder arthroplasty outcomes. J Shoulder Elb Surg. 2017; https://doi.org/10.1016/j.jse.2017.05.016.

Chou R, Qaseem A, Snow V, Casey D, Cross JT Jr, Shekelle P, et al. Diagnosis and treatment of low back pain: a joint clinical practice guideline from the American College of Physicians and the American Pain Society. Ann Intern Med. 2007;147:478-91. Erratum in: Ann Intern Med. 2008;148:247-8

Collett BJ. Opioid tolerance: the clinical perspective. Br J Anaesth. 1998;81:58-68.

Comelon M, Raeder J, Stubhaug A, Nielsen CS, Draegni T, Lenz H, Colvin L. Gradual withdrawal of remifentanil infusion may prevent opioid-induced hyperalgesia. Br J Anaesth. 2016;116:524-30.

Compton P, Athanasos P, Elashoff D. Withdrawal hyperalgesia after acute opioid physical dependence in nonaddicted humans: a preliminary study. J Pain. 2003; 4:511-9.

Cooper ZD, Sullivan MA, Vosburg SK, Manubay JM, Haney M, Foltin RW, et al. Effects of repeated oxycodone administration on its analgesic and subjective effects in normal, healthy volunteers. Behav Pharmacol. 2012;23:271-9.

Coronado RA, George SZ, Devin CJ, et al. Pain sensitivity and pain catastrophizing are associated with persistent pain and disability after lumbar spine surgery. Arch Phys Med Rehabil. 2015;96:1763-70.

Darnall BD. Pain psychology and pain catastrophizing in the perioperative setting: a review of impacts, interventions and unmet needs. Hand Clin. 2016;32:33-9.

Denison E, Åsenlöf P, Lindberg P. Self-efficacy, fear avoidance, and pain intensity as predictors of disability in subacute and chronic musculoskeletal pain patients in primary health care. Pain. 2004;111:245-52.

Desebbe O, Lanz T, Kain Z, Cannesson M. The perioperative surgical home: an innovative, patient-centred and cost-effective perioperative care model. Anaesth Crit Care Pain Med. 2016;35:59-66.

Faour M, Anderson JT, Haas AR, Percy R, Woods ST, Ahn UM, Ahn NU. Neck pain, preoperative opioids, and functionality after cervical fusion. Orthopedics. 2017:40:25-32.

Farmer MA, Baliki MN, Apkarian AV. A dynamic network perspective of chronic pain. Neurosci Lett. 2012;520:197-203.

Fechner J, Ihmsen H, Schuttler J, Jeleazcov C. The impact of intraoperative sufentanil dosing on postoperative pain, hyperalgesia and morphine consumption after cardiac surgery. Eur J Pain. 2013;17:562-70.

Federation of State Medical Boards. Model policy on the use of opioid analgesics in the treatment of chronic pain. 2013 Downloaded from http://www.fsmb. org/Media/Default/PDF/FSMB/Advocacy/pain_policy_july2013.pdf. Accessed 6 Aug 2017

Fishbain DA, Cutler BR, Rosomoff HL, Rosomoff RS. Comorbidity between psychiatric disorders and chronic pain. Curr Rev Pain. 1998;2:1-10.

Fletcher D, Martinez V. Opioid-induced hyperalgesia in patients after surgery: a systematic review and a meta-analysis. Br J Anaesth. 2014;112:991-1004.

Flor H, Braun C, Elbert T, Birbaumer N. Extensive reorganization of primary somatosensory cortex in chronic back pain patients. Neurosci Lett. 1997;224:5-8.

Goldner EM, Lusted A, Roerecke M, Rehm J, Fischer B. Prevalence of Axis-1 psychiatric (with focus on depression and anxiety) disorder and symptomatology among non-medical prescription opioid users in substance use treatment: systematic review and meta-analyses. Addict Behav. 2014;39:520-31.

Gross R, Long D, Cox S. (197) Predicting opioid misuse with a brief screener of catastrophizing. J Pain. 2016;17(4S):S25.

Guignard B, Bossard AE, Coste C, Sessler DI, Lebrault C, Alfonsi P, et al. Acute opioid tolerance: intraoperative remifentanil increases postoperative pain and morphine requirement. Anesthesiology. 2000;93:409-17.

Gureje O, Von Korff M, Kola L, Demyttenaere K, He Y, Posada-Villa J, et al. The relation between multiple pains and mental disorders: results from the world mental health surveys. Pain. 2008;135:82-91.

Hah JM, Sharifzadeh Y, Wang BM, Gillespie MJ, Goodman SB, Mackey SC, et al. Factors associated with opioid use in a cohort of patients presenting for surgeny. Pain Res Treat. 2015;2015:829696. https:/doi.org/10.1155/2015/829696.

Harris IA, Young JM, Rae H, Jalaludin BB, Solomon MJ. Factors associated with back pain after physical injury: a survey of consecutive major trauma patients. Spine (Phila Pa 1976). 2007;32:1561-5. 
Heinricher MM, Tavares I, Leith JL, Lumb BM. Descending control of nociception: specificity, recruitment and plasticity. Brain Res Rev. 2009;60:214-25.

Hina N, Fletcher D, Poindessous-Jazat F, Martinez V. Hyperalgesia induced by low-dose opioid treatment before orthopaedic surgery: an observational case-control study. Eur J Anaesthesiol. 2015;32:255-61.

Hoofwijk DM, Fiddelers AA, Peters ML, Stessel B, Kessels AG, Joosten EA, et al. Prevalence and predictive factors of chronic postsurgical pain and poor global recovery one year after outpatient surgery. Clin J Pain. 2015; Epub

International Association for the Study of Pain. IASP sponsors global year against pain after surgery. 2017. Available at: https://www.iasp-pain.org/files/ 2017GlobalYear/News\%20Release\%20for\%202017\%20Global\%20Year.pdf. Accessed 4 Aug 2017.

Ip HY, Abrishami A, Peng PW, et al. Predictors of postoperative pain and analgesic consumption: a qualitative systematic review. Anesthesiology. 2009;111:657-77.

Jenewein J, Moergeli H, Wittmann L, Büchi S, Kraemer B, Schnyder U. Development of chronic pain following severe accidental injury. Results of a 3-year follow-up study. J Psychosom Res. 2009;66:119-26.

Katz C, El-Gabalawy R, Keyes KM, Martins SS, Sareen J. Risk factors for incident nonmedical prescription opioid use and abuse and dependence: results from a longitudinal nationally representative sample. Drug Alcohol Depend. 2013; 132:107-13.

Katz J, Weinrib A, Fashler SR, Katznelzon R, Shah BR, Ladak SS, et al. The Toronto General Hospital Transitional Pain Service: development and implementation of a multidisciplinary program to prevent chronic postsurgical pain. J Pain Res. 2015;8:695-702.

Kelly MP, Anderson PA, Sasso RC, Riew KD. Preoperative opioid strength may not affect outcomes of anterior cervical procedures: a post hoc analysis of 2 prospective, randomized trials. J Neurosurg Spine. 2015;23:484-9.

Khan RS, Ahmed K, Blakeway E, et al. Catastrophizing: a predictive factor for postoperative pain. Am J Surg. 2011;201:122-31.

Kleiman V, Clarke H, Katz J. Sensitivity to pain traumatization: a higher-order factor underlying pain-related anxiety, pain catastrophizing and anxiety sensitivity among patients scheduled for major surgery. Pain Res Manag. 2011;16:169-77.

Lally P, van CHM J, HWW P, Wardle J. How are habits formed: modelling habit formation in the real world. Eur J Soc Psychol. 2010;40:998-1009.

Latremoliere A, Woolf CJ. Central sensitization: a generator of pain hypersensitivity by central neural plasticity. J Pain. 2009;10:895-926.

Lawrence JT, London N, Bohlman HH, Chin KR. Preoperative narcotic use as a predictor of clinical outcome: results following anterior cervical arthrodesis. Spine (Phila Pa 1976). 2008a;(33):2074-8.

Lawrence JTR, London N, Bohlman HH, Chin KR. Preoperative narcotic use as a predictor of clinical outcome: results following anterior cervical arthrodesis. Spine. 2008b;33:2074-8.

Lee M, Silverman SM, Hansen H, Patel VB, Manchikanti L. A comprehensive review of opioid-induced hyperalgesia. Pain Physician. 2011;14:145-61.

Malik OS, Kaye AD, Urman RD. Perioperative hyperalgesia and associated clinical factors. Curr Pain Headache Rep. 2017;21:4.

Malinen S, Vartiainen N, Hlushchuk Y, Koskinen M, Ramkumar P, Forss N, et al. Aberrant temporal and spatial brain activity during rest in patients with chronic pain. Proc Natl Acad Sci U S A. 2010;107:6493-7.

Manchikanti L, Kaye AM, Knezevic NN, McAnally H, Slavin K, Trescot AM, et al. Responsible, safe, and effective prescription of opioids for chronic non-cancer pain: American Society of Interventional Pain Physicians (ASIPP) guidelines. Pain Physician. 2017;20(2S):S3-S92.

Martins SS, Fenton MC, Keyes KM, Blanco C, Zhu H, Storr CL. Mood/anxiety disorders and their association with non-medical prescription opioid use and prescription opioid use disorder: longitudinal evidence from the National Epidemiologic Study on alcohol and related conditions. Psychol Med. 2012;42:1261-72.

Mauermann E, Filitz J, Dolder P, Rentsch KM, Bandschapp O, Ruppen W. Does Fentanyl lead to opioid-induced hyperalgesia in healthy volunteers?: a double-blind, randomized. Crossover Trial Anesthesiology. 2016;124:453-63.

McAnally HB. Opioid dependence risk factors and risk assessment. In: McAnally HB, opioid dependence: a clinical and epidemiologic approach. New York: Springer. p. 2017.

Menendez ME, Ring D, Bateman BT. Preoperative opioid misuse is associated with increased morbidity and mortality after elective orthopaedic surgery. Clin Orthop Relat Res. 2015;473:2402-12.

Morris BJ, Laughlin MS, Elkousy HA, Gartsman GM, Edwards TB. Preoperative opioid use and outcomes after reverse shoulder arthroplasty. J Shoulder Elb Surg. 2015;24:11-6.
Morris BJ, Sciascia AD, Jacobs CA, Edwards TB. Preoperative opioid use associated with worse outcomes after anatomic shoulder arthroplasty. J Shoulder Elb Surg. 2016;25:619-23.

Nguyen LC, Sing DC, Bozic KJ. Preoperative reduction of opioid use before total joint arthroplasty. J Arthroplast. 2016;31(9 Suppl):282-7.

Pivec R, Issa K, Naziri Q, Kapadia BH, Bonutti PM, Mont MA. Opioid use prior to total hip arthroplasty leads to worse clinical outcomes. Int Orthop. 2014;38: 1159-65.

Quartana PJ, Campbell CM, Edwards RR. Pain catastrophizing: a critical review. Expert Rev Neurother. 2009;9:745-58.

Raebel MA, Newcomer SR, Reifler LM, Boudreau D, Elliott TE, DeBar L, et al. Chronic use of opioid medications before and after bariatric surgery. JAMA. 2013;310:1369-76.

Rodriguez-Raecke R, Niemeier A, Ihle K, Ruether W, May A. Brain gray matter decrease in chronic pain is the consequence and not the cause of pain. J Neurosci. 2009;29:13746-50

Roeckel LA, Le Coz GM, Gavériaux-Ruff C, Simonin F. Opioid-induced hyperalgesia: cellular and molecular mechanisms. Neuroscience. 2016;338: $160-82$.

Roullet S, Nouette-Gaulain K, Biais M, Bernard N, Bénard A, Revel P, et al. Preoperative opioid consumption increases morphine requirement after leg amputation. Can J Anaesth. 2009;56:908-13.

Rozell JC, Courtney PM, Dattilo JR, Wu CH, Lee GC. Preoperative opiate use independently predicts narcotic consumption and complications after total joint arthroplasty. J Arthroplast. 2017; https://doi.org/10.1016/j.arth.2017.04.002.

Rozet I, Nishio I, Robbertze R, Rotter D, Chansky H, Hernandez AV. Prolonged opioid use after knee arthroscopy in military veterans. Anesth Analg. 2014; 119:454-9.

Salengros J-C, Huybrechts I, Ducart A, Faraoni D, Marsala C, Barvais L, et al. Different anesthetic techniques associated with different incidences of chronic post-thoracotomy pain: low dose remifentanil plus pre-surgical epidural analgesia is preferable to high dose remifentanil with postsurgical epidural analgesia. J Cardiothorac Vasc Anesth. 2010;24:608-16.

Schmidt-Wilcke T. Variations in brain volume and regional morphology associated with chronic pain. Curr Rheumatol Rep. 2008;10:467-74.

Simons LE, Elman I, Borsook D. Psychological processing in chronic pain: a neural systems approach. Neurosci Biobehav Rev. 2014;39:61-78.

Sing DC, Barry JJ, Cheah JW, Vail TP, Hansen EN. Long-acting opioid use independently predicts perioperative complication in total joint arthroplasty. J Arthroplast. 2016;31(9 Suppl):170-4.

Smith SR, Bido J, Collins JE, Yang H, Katz JN, Losina E. Impact of preoperative opioid use on total knee arthroplasty outcomes. J Bone Joint Surg Am. 2017; 99:803-8.

Sullivan MJL, Bishop SR, Pivik J. The pain catastrophizing scale: development and validation. Psychol Assess. 1995;7:524-32.

Teunis T, Bot AG, Thornton ER, Ring D. Catastrophic thinking is associated with finger stiffness after distal radius fracture surgery. J Orthop Trauma. 2015 Oct; 29(10):e414-20.

Theunissen M, Peters ML, Bruce J, Gramke HF, Marcus MA. Preoperative anxiety and catastrophizing: a systematic review and meta-analysis of the association with chronic postsurgical pain. Clin J Pain. 2012;28:819-41.

Tinazzi M, Zanette G, Volpato D, Testoni R, Bonato C, Manganotti P, Miniuissi C, Fiachi A. Neurophysiological evidence of neuroplasticity at multiple levels of the somatosensory system in patients with carpal tunnel syndrome. Brain. 1998:121:1785-94.

Tracey I, Mantyh PW. The cerebral signature for pain perception and its modulation. Neuron. 2007;2:377-91.

Trevino CM, deRoon-Cassini T, Brasel K. Does opiate use in traumatically injured individuals worsen pain and psychological outcomes? J Pain. 2013;14:424-30.

Turk DC, Swanson KS, Gatchel RJ. Predicting opioid misuse by chronic pain patients: a systematic review and literature synthesis. Clin J Pain. 2008;24:497-508.

Tye EY, Anderson J, Faour M, Haas A, Percy R, Woods ST, Ahn UM, Ahn N. Prolonged preoperative opioid therapy in patients with degenerative lumbar stenosis in a workers' compensation setting. Spine (Phila Pa 1976). 2017; https://doi.org/10.1097/BRS.0000000000002112.

United States Department of Health and Human Services. National Pain Strategy: a comprehensive population health-level strategy for pain. 2016 Downloaded from https://iprcc.nih.gov/sites/default/files/HHSNational_Pain_ Strategy_508C.pdf. Accessed 6 Aug 2017.

VanDenKerkhof EG, Hopman WM, Goldstein DH, Wilson RA, Towheed TE, Lam M, et al. Impact of perioperative pain intensity, pain qualities, and opioid use on 
chronic pain after surgery: a prospective cohort study. Reg Anesth Pain Med. 2012;37:19-27.

Veterans Health Administration and Department of Defense. VHA/DoD clinical practice guideline for the management of postoperative pain. 2002. Downloaded from https://www.healthquality.va.gov/guidelines/Pain/pop/ pop_fulltext.pdf. Accessed 4 Aug 2017.

Vetter TR, Kain ZV. Role of the perioperative surgical home in optimizing the perioperative use of opioids. Anesth Analg. 2017; https://doi.org/10.1213/ ANE.0000000000002280. [Epub ahead of print]

Villavicencio AT, Nelson EL, Kantha V, Burneikiene S. Prediction based on preoperative opioid use of clinical outcomes after transforaminal lumbar interbody fusions. J Neurosurg Spine. 2017;26:144-9.

Vissers MM, Bussmann JB, Verhaar JA, Busschbach JJ, Bierma-Zeinstra SM, Reijman M. Psychological factors affecting the outcome of total hip and knee arthroplasty: a systematic review. Semin Arthritis Rheum. 2012:41:576-88.

Von Korff N, Crane P, Lane M, Miglioretti DL, Simon G, Saunders K, et al. Chronic spinal pain and physical-mental comorbidity in the United States: results from the national comorbidity survey replication. Pain. 2005;113:331-9.

Waljee JF, Cron DC, Steiger RM, Zhong L, Englesbe MJ, Brummett CM. Effect of preoperative opioid exposure on healthcare utilization and expenditures following elective abdominal surgery. Ann Surg. 2017;265:715-21.

Wanigasekera V, Lee MC, Rogers R, Hu P, Tracey I. Neural correlates of an injuryfree model of central sensitization induced by opioid withdrawal in humans. J Neurosci. 2011:31:2835-42.

Weber L, Yeomans DC, Tzabazis A. Opioid-induced hyperalgesia in clinical anesthesia practice: what has remained from theoretical concepts and experimental studies? Curr Opin Anaesthesiol. 2017;30:458-65.

Weinbroum AA. Postoperative hyperalgesia-a clinically applicable narrative review. Pharmacol Res. 2017;120:188-205.

Williams JT, Ingram SL, Henderson G, Chavkin C, von Zastrow M, Schulz S, et al. Regulation of $\mu$-opioid receptors: desensitization, phosphorylation, internalization, and tolerance. Pharmacol Rev. 2013;65:223-54.

Younger JW, Chu LF, D'Arcy NT, Trott KE, Jastrzab LE, Mackey SC. Prescription opioid analgesics rapidly change the human brain. Pain. 2011;152:1803-10.

Zarling BJ, Yokhana SS, Herzog DT, Markel DC. Preoperative and postoperative opiate use by the arthroplasty patient. J Arthroplast. 2016;31:2081-4.

Zywiel MG, Stroh DA, Lee SY, Bonutti PM, Mont MA. Chronic opioid use prior to total knee arthroplasty. J Bone Joint Surg Am. 2011;93:1988-93.

\section{Submit your next manuscript to BioMed Central and we will help you at every step:}

- We accept pre-submission inquiries

- Our selector tool helps you to find the most relevant journal

- We provide round the clock customer support

- Convenient online submission

- Thorough peer review

- Inclusion in PubMed and all major indexing services

- Maximum visibility for your research

Submit your manuscript at www.biomedcentral.com/submit

) Biomed Central 